\title{
THE EVOLVING PUBLIC HEALTH LABORATORY SYSTEM
}

Frances Pouch Downes, DrPH John C. Ridderhof, DrPH
Charles Darwin's On the Origin of Species celebrated its 150th anniversary in 2009. ${ }^{1}$ In this publication that has shaped our understanding of biology, the author proposes that organisms evolve increasingly complex independent and interdependent systems to survive and flourish in an ever-changing environment. The evolution of public health laboratories (PHLs) can be compared with that of multi-celled organisms. PHL history tracks the progress from simply having laboratory testing available for public health programs to the development and fine-tuning of laboratory networks requiring special linkages and shared efforts to provide populations with comprehensive laboratory testing for rapid diagnosis, surveillance, and disease-control efforts. The evolution, from a PHL to the new definition of a PHL system that includes public and private laboratories, is reflected by a new focus on the relationships between laboratories, which complement the technical capabilities-similar to the increasingly complex interactions of multi-celled organisms responding to a changing environment.

Focus and attention on laboratories as part of a broader public health system has accelerated in recent years with several key events and activities. In 2001, the Association of Public Health Laboratories (APHL) and the Centers for Disease Control and Prevention (CDC) published the 11 Core Functions and Capabilities of State Public Health Laboratories (hereafter, Core Functions), ${ }^{2}$ representing broad consensus on basic laboratory services, in addition to leadership in developing state networks. The introduction of the National Laboratory System by CDC in 2000 started a conversation among PHLs nationwide regarding the need for such a system in each state and the role of the PHL in convening and nurturing the system. ${ }^{3}$ The article in this supplement by Inhorn et al. describes the development of a State Public Health Laboratory System (SPH Laboratory System) in the U.S. ${ }^{4}$ These state systems collectively are related to several other recent PHL initiatives. In addition to the Core Functions, which describe what services every state PHL should provide or assure is provided, APHL launched in 2004 a State Public Health Laboratory System Improvement Program. ${ }^{5}$ That same year, APHL developed a Comprehensive Laboratory Services Survey, a tool to measure improvement through the decade to assure essential PHL services are provided and track progress toward Healthy People 2010 goals and Objective $23-13 .{ }^{6,7}$

The final impetus to develop PHL systems was the threat of biological and chemical terrorism. The anthrax attacks in late 2001 emphasized that effective communications between public and private laboratories with rapid referral of isolates provided by the Laboratory Response Network (LRN) was a requisite to preparing for any public health emergency or threat. ${ }^{8}$ The LRN assures that 
clinicians caring for ill people throughout the U.S. will have access to rapid, accurate diagnostics for agents of biological and chemical terrorism. A web of clinical microbiology laboratories and emergency care facilities is linked to local clinical laboratories that perform initial testing and then rapidly forward suspect isolates to state and local PHLs in all states for confirmation of biological terrorism agents. The cover of this issue includes an image of a map as an example of the need for states and jurisdictions to plan for response and consider location when coordinating referral. Specimens from people potentially exposed to chemical terrorism agents are forwarded to a smaller number of specially equipped and staffed state PHLs. The LRN has proven useful in responding to additional public health threats. Whelan et al. present a robust example of the potential for network gain, describing the integration of real-time reverse transcription polymerase chain reaction screening into a statewide algorithm for influenza surveillance and response. ${ }^{9}$

PHLs have adapted in the past century to respond to a variety of political, technical, and laboratory industry changes. In the early 20th century, pioneering state boards of health established PHLs where the nascent science of bacteriology could be applied to identifying the cause(s) of diseases and finding control measures for prevention. Prior to the growth of clinical laboratories in hospitals, PHLs were the source of routine testing for physicians bringing science to the practice of medicine. Additionally, they were the first food-safety and environmental laboratories monitoring milk, food, and water to protect communities from population-based health risks. PHLs went on to establish research programs for vaccine and diagnostic-test development. In 2000, CDC reviewed the 10 developments of the 20th century that led to U.S. life-expectancy gains. ${ }^{10}$ PHLs played a major role in accomplishing eight of the 10 developments (vaccination, control of infectious diseases, decline in deaths from coronary heart disease, safer foods, healthier mothers and babies, family planning, and safe drinking water), which involved some component of laboratory testing/measurement.

As the laboratory sciences of microbiology, chemistry, and molecular biology advanced during the 1900 s, many new roles were created for PHLs, and organizations took on housing their own laboratories, as testing originally performed solely in PHLs transitioned to specialized laboratories. Many government laboratories charged with regulating and assuring food and environmental safety were relocated from public health to new environmental or agricultural agencies. Appreciation that these are still PHLs is evident in the name and membership of the leading advocacy organization representing PHLs in the U.S.- the APHL. Vaccine production and diagnostic-test development transitioned to the private sector and academia. PHLs, however, retained many roles, including data management ${ }^{11}$ and applied research, with some state PHLs as part of university systems.

Applied research is the basis for evidence-based PHL practice, as evidenced in this supplement by Baker et al., who describe scientific, technical, ethical, and policy issues that must be addressed prior to the addition of a new condition to a state newborn screening test panel. ${ }^{12}$ The authors present findings of the recent experience in adding a test for severe combined immunodeficiency (SCID) to Wisconsin's panel of newborn screening tests.

While PHLs still provide state-of-the-art testing services to address population-based testing needs, the clinical laboratory sector has grown and now provides most of the testing for patient diagnosis, management, and treatment. This has enabled the PHL to progressively expand its expertise and position in state or local government public health agencies to provide additional services. ${ }^{13,14}$ Wilson et al. describe the pivotal role of local PHLs within networks and in addressing community needs in this supplement. ${ }^{15}$ While routine patient testing is largely performed in clinical laboratories, the results of this testing are often needed for public health disease surveillance activities; hence, PHLs have a core function to advocate for quality testing throughout the laboratory system. ${ }^{16,17}$ As indicated in the Core Functions and as evidenced in the article by Boehme et al., the quality of surveillance data relies on the accuracy of results from clinical laboratories. ${ }^{18}$ The authors propose improving accuracy through technical support and ongoing review of cumulative antibiograms.

The environment in which PHLs exist is dynamic: maturation of laboratory sciences and emerging technology; an increasingly complex health-care system; emphasis on smaller government and public-funds spending constraints; emerging infectious diseases; environmental health concerns; and use of biological, chemical, or radiological agents as weapons are all issues that affect PHLs. Not only have specialized laboratories emerged, but it also is increasingly appreciated that public health testing needs cannot successfully be assured or provided solely by PHLs. A formal network with other laboratories (clinical, environmental, and agricultural), public health programs, law enforcement, and academia is needed..$^{19}$ As in a well-adapted, successful organism, the system's parts must work in concert to achieve a single goal. In this case, the goal 
is access to the comprehensive and quality services laid out in the Core Functions.

In a complex organism, systems do not work independently of each other; they work in concert, each performing independent tasks that cumulatively achieve growth and success of the organism. Similarly, an SPH Laboratory System connects states with each other, federal laboratories, public health programs, academia, and clinical laboratories to form a national network working toward a common output-improved health of the population. ${ }^{20,21}$ A description of one widely heralded private-public laboratory network, PulseNet, is provided in this supplement by Boxrud et al. ${ }^{22}$ To better represent and convey the different components of effective laboratory systems, the articles in this supplement are ordered according to the Core Functions.

This supplemental issue of Public Health Reports represents a watershed event in the evolution of the PHL toward an integrated system. In addition to articles that provide evidence for PHL testing program improvements, there are articles that describe the emerging function of PHLs in developing and maintaining networks. To form robust networks, the PHL community has also reached out to nontraditional partners ${ }^{5}$ and nontraditional activities. ${ }^{18}$ State and local PHLs have complementary roles in developing, nurturing, and maintaining networks that respond to regional or local needs.

Ronald Laessig, one of the authors of the article by Baker et al., ${ }^{12}$ passed away prior to publication of this supplement. His lifetime of leadership and contributions to the body of evidence that promotes excellence in the PHL community confirm that the efforts of a committed, gifted individual will be realized for generations.

We thank the staff and Laboratory System Committee of APHL, especially Stanley Inhorn and Burt Wilcke, for their contributions and vision in developing this supplement, and CDC's Division of Laboratory Systems for its support. PHL system development is an ongoing process. While progress is evident from the breadth and depth of topics addressed in this supplement, it does not represent an end point but, rather, a snapshot of the evolutionary continuum. Political, technical, and health-care system forces will continue to open new niches for the vitality and adaptable organism that is the PHL.

Frances Pouch Downes is the State Laboratory Director at the Michigan Department of Community Health in Lansing, Michigan. John Ridderhof is the Associate Director for Laboratory Science at the National Center for Preparedness, Detection, and Control of Infectious Diseases, Centers for Disease Control and Prevention in Atlanta, Georgia.
Address correspondence to: Frances Pouch Downes, DrPH, Michigan Department of Community Health, 3350 N. Martin Luther King, Jr. Blvd., Lansing, MI 48909; tel. 517-335-8063; fax 517-335-8051; e-mail <downesf@michigan.gov>.

\section{REFERENCES}

1. Darwin C. On the origin of the species. London: John Murray; 1859.

2. Witt-Kushner J, Astles JR, Ridderhof JC, Martin RA, Wilcke B Jr, Downes FP, et al. Core functions and capabilities of state public health laboratories: a report of the Association of Public Health Laboratories. MMWR Recomm Rep 2002;51(RR-14):1-8.

3. Astles JR, White VA, Williams LO. Origins and development of the national laboratory system for public health testing. Public Health Rep 2010;125(Suppl 2):18-30.

4. Inhorn SL, Astles JR, Gradus S, Malmberg V, Snippes PM, Wilcke BW $\mathrm{Jr}$, et al. The state public health laboratory system. Public Health Rep 2010;125(Suppl 2):4-17.

5. Milne KC, Milne TL. Public health laboratory system improvement program: development and implementation. Public Health Rep 2010;125(Suppl 2):31-9.

6. Inhorn SL, Wilcke BW Jr, Downes FP, Adjanor OO, Cada R, Ford JR. A Comprehensive Laboratory Services Survey of State Public Health Laboratories. J Public Health Manag Pract 2006;12:514-21.

7. Department of Health and Human Services (US). Healthy People 2010: understanding and improving health. 2nd ed. Washington: HHS; 2000.

8. Biological and chemical terrorism: strategic plan for preparedness and response. MMWR Recomm Rep 2000;49(RR-04):1-14.

9. Whelen AC, Bankowski MJ, Furuya G, Honda S, Ueki R, Chan A, et al. Pandemic preparedness in Hawaii: a multicenter verification of real-time RT-PCR for the direct detection of influenza virus types A and B. Public Health Rep 2010;125(Suppl 2):81-7.

10. Ten great public health achievements-United States, 1900-1999. MMWR Morb Mortal Wkly Rep 1999;48(12):241-3.

11. Zarcone P, Nordenberg D, Meigs M, Merrick U, Jernigan D, Hinrichs $\mathrm{SH}$. Community-driven standards-based electronic laboratory datasharing networks. Public Health Rep 2010;125(Suppl 2):47-56.

12. Baker MW, Laessig RH, Katcher ML, Routes JM, Grossman WJ, Verbsky J, et al. Implementing routine testing for severe combined immunodeficiency within Wisconsin's Newborn Screening Program. Public Health Rep 2010;125(Suppl 2):88-95.

13. DeBoy JM, Luedtke P, Warren N, Wichman M. Basic personnel tools to help ensure a future public health and environmental laboratory workforce. Public Health Rep 2010;125(Suppl 2):96-101.

14. Blumen SR, Naud S, Palumbo MV, McIntosh B, Wilcke BW Jr. Knowledge and perceptions of quality systems among Vermont laboratorians. Public Health Rep 2010;125(Suppl 2):73-80.

15. Wilson ML, Gradus S, Zimmerman SJ. The role of local public health laboratories. Public Health Rep 2010;125(Suppl 2):118-22.

16. Wilcke BW Jr, Inhorn SL, Astles JR, Su B, Wright A, White VA. Laboratory services in support of public health: a status report. Public Health Rep 2010;125(Suppl 2):40-6.

17. McDade JE, Hughes JM. The U.S. needs a national laboratory system. US Med 1998;34:9.

18. Boehme MS, Somsel PA, Downes FP. Systematic review of antibiograms: a national laboratory system approach for improving antimicrobial susceptibility testing practices in Michigan. Public Health Rep 2010;125(Suppl 2):63-72.

19. Skeels MR. Toward a national laboratory system for public health. Emerg Infect Dis 2001;7(Suppl 3):531-2.

20. Kirk CJ, Shult PA. Developing laboratory networks: a practical guide and application. Public Health Rep 2010;125(Suppl 2):102-9.

21. Marshall SA, Brokopp CD, Size T. Leadership principles for developing a statewide public health and clinical laboratory system. Public Health Rep 2010;125(Suppl 2):110-7.

22. Boxrud D, Monson T, Stiles T, Besser J. The role, challenges, and support of PulseNet laboratories in detecting foodborne disease outbreaks. Public Health Rep 2010;125(Suppl 2):57-62 